\title{
NADPH oxidase 2-derived reactive oxygen species signal contributes to bradykinin-induced matrix metalloproteinase- 9 expression and cell migration in brain astrocytes
}

Chih-Chung Lin ${ }^{1 \dagger}$, Hsi-Lung Hsieh ${ }^{2 \dagger}$, Ruey-Horng Shih ${ }^{3}$, Pei-Ling Chi ${ }^{3}$, Shin-Ei Cheng ${ }^{3}$, Jin-Chung Chen ${ }^{3}$ and Chuen-Mao Yang ${ }^{3 *}$

\begin{abstract}
Background: Matrix metalloproteinase-9 (MMP-9) plays a crucial role in pathological processes of brain inflammation, injury, and neurodegeneration. Moreover, bradykinin (BK) induces the expression of several inflammatory proteins in brain astrocytes. Recent studies have suggested that increased oxidative stress is implicated in the brain inflammation and injury. However, whether BK induced MMP-9 expression mediated through oxidative stress remains virtually unknown. Herein we investigated the role of redox signals in BK-induced MMP-9 expression in rat brain astrocytes (RBA-1 cells).

Results: In the study, we first demonstrated that reactive oxygen species (ROS) plays a crucial role in BK-induced MMP-9 expression in cultured brain astrocytes (in vitro) and animal brain tissue (in vivo) models. Next, BK-induced MMP-9 expression is mediated through a $\mathrm{Ca}^{2+}$-mediated PKC-a linking to $\mathrm{p} 47^{\text {phox }} / \mathrm{NADPH}$ oxidase 2 (Nox2)/ROS signaling pathway. Nox2-dependent ROS generation led to activation and up-regulation of the downstream transcriptional factor AP-1 (i.e. c-Fos and c-Jun), which bound to MMP-9 promoter region, and thereby turned on transcription of MMP-9 gene. Functionally, BK-induced MMP-9 expression enhanced astrocytic migration.
\end{abstract}

Conclusions: These results demonstrated that in RBA-1 cells, activation of AP-1 (c-Fos/c-Jun) by the PKC-a-mediated Nox2/ROS signals is essential for up-regulation of MMP-9 and cell migration enhanced by BK.

Keywords: Brain inflammation, Astrocytes, Bradykinin, Matrix metalloproteinase-9, NADPH oxidase, Reactive oxygen species

\section{Background}

Matrix metalloproteinases (MMPs) is a large family of zinc-dependent endopeptidases, which play an important role in the turnover of extracellular matrix (ECM) and pathophysiological processes [1]. In the central nervous system (CNS), MMPs, in particular MMP-9, have been shown to be involved in morphogenesis, wounding healing, and neurite outgrowth, [2]. Up-regulation of MMP9 has been induced by various brain injuries, which may

\footnotetext{
* Correspondence: chuenmao@mail.cgu.edu.tw

${ }^{\dagger}$ Equal contributors

${ }^{3}$ Department of Physiology and Pharmacology and Health Aging Research Center, College of Medicine, Chang Gung University, 259 Wen-Hwa 1st Road, Kwei-San, Tao-Yuan, Taiwan

Full list of author information is available at the end of the article
}

participate in the pathogenesis of brain diseases [3]. Moreover, cytokines and lipopolysaccharide (LPS) have been shown to induce MMP-9 expression and activity in culture rat brain astrocytes $[4,5]$. These studies demonstrated that MMP-9 may be involved in brain inflammation and injury.

Reactive oxygen species (ROS) are produced by various enzymatic and chemical processes or directly inhaled, including $\mathrm{O}_{2}^{-}, \cdot \mathrm{OH}$, and hydrogen peroxide $\left(\mathrm{H}_{2} \mathrm{O}_{2}\right)$. The ROS at low level have physiological roles as signaling molecules in various cellular and developmental processes [6,7] and killing of invading microorganisms [8]. In contrast, recent report indicated that oxidative stress plays an important role in the progression of various

\section{() Biomed Central}

(C) 2012 Lin et al.; licensee BioMed Central Ltd. This is an Open Access article distributed under the terms of the Creative Commons Attribution License (http://creativecommons.org/licenses/by/2.0), which permits unrestricted use, distribution, and reproduction in any medium, provided the original work is properly cited. 
diseases [8]. Moreover, ROS has been shown to interact with DNA, lipids, proteins, and carbohydrates that lead to cellular dysfunctions and inflammatory responses $[7,9]$. Under pathological conditions, many proinflammatory mediators like bradykinin (BK) induce expression of several inflammatory genes during brain injury by increasing ROS production $[7,10]$. Recently, increasing evidence attributes the neurodegenerative diseases such as Alzheimer's disease (AD) to oxidative stress (generation of free radicals) that leads to brain inflammation during CNS pathogenesis $[7,10,11]$. Moreover, ROS also exert as a signaling factor mediated microglial activation induced by several proinflammatory mediators [12]. Although the effects of BK associated with ROS generation have been reported in several organ diseases [13], BK-induced ROS-mediated MMP-9 responses are not well characterized in rat brain astrocytes (RBA-1) cells.

BK and related peptides are elevated during brain trauma, stroke, and neuroinflammation [14]. Among brain cells, astrocytes possess a B2-type BK receptor which is a $\mathrm{G}$ protein-coupled receptor (GPCR) coupling to a $G_{q}$ protein to activate PLC $\beta$, phosphoinositide breakdown, $\mathrm{Ca}^{2+}$ mobilization, PKC, and ROS generation $[15,16]$. These signaling pathways regulate several cellular responses including proliferation, migration, and gene expression. Moreover, the 5 ' region of MMP-9 promoters has been characterized to possess a series of functional enhancer element-binding sites such as NF$\kappa B$, Ets, and AP-1 [17]. BK has been shown to regulate expression of several genes through different transcription factors including AP-1 [18] and NF- $\mathrm{KB}$ [19]. In astrocytes, MMP-9 expression induced by various stimuli was mediated through activation of either NF-kB or AP-1 [20-22]. However, the molecular mechanisms of ROS associated with MMP-9 expression and cellular function (motility) induced by BK in RBA-1 cells are not completely defined.

Accordingly, BK may play an important role in regulation of ROS signal and specific gene expression, such as MMP-9 and enhancing inflammatory responses. The experiments were performed to investigate the molecular mechanisms of ROS signaling pathways involved in BK-induced MMP-9 expression in RBA-1 cells and an animal model. In the study, we found that BK induces MMP-9 expression via a ROS-dependent pathway. A $\mathrm{Ca}^{2+} / \mathrm{PKC}-\alpha$-dependent Nox2/ROS generation cascade contributes to AP-1 induction and activation, which is required for MMP-9 expression and cell motility in RBA-1 cells.

\section{Results}

BK induces MMP-9 expression via ROS-dependent manner ROS have been shown to induce MMPs expression in various cell types [23]. To determine whether ROS participates in MMP-9 induction, a ROS scavenger (NAC) was used. Pretreatment with a NAC (10 mM) attenuated BK-induced MMP-9 protein and mRNA expression (Figure 1A, B). To explore BK-stimulated ROS generation and the efficacy of NAC, a ROS indicator (DCF-DA) was used. As shown in Figure 1C, BKstimulated ROS generation was attenuated by pretreatment with NAC, demonstrating that NAC can efficiently scavenge ROS in these cells. To further investigate whether BK induces MMP-9 transcription activity via ROS-dependent manner, a rat MMP-9 promoter reporter-luciferase construct was used. The data showed that BK stimulated an increase of MMP-9 promoter activity which was attenuated by pretreatment with NAC (Figure 1D). These results suggested that ROS contribute to BK-induced MMP-9 expression via enhancing its gene transcriptional activity in RBA-1 cells.

We further confirmed whether BK-induced ROSdependent MMP-9 expression also occurred in rat brain cortex tissue (in vivo). As shown in Figure 1E, the images of immunofluorescence staining showed that injection with BK induced MMP-9 expression as compared with that of control (sham), which was attenuated by pretreatment with NAC in rat brain cortex tissue. Consistently, pretreatment with NAC markedly attenuated BK-induced MMP-9 protein and mRNA expression (in vivo) determined by Western blot, gelatin zymography, and real-time PCR, demonstrating that BK induces MMP-9 gene expression via a ROS-dependent manner in in vivo studies. To further confirm BK-induced ROSdependent MMP-9 expression in brain astrocytes, the rat brain primary astrocytes were isolated and cultured. As expected, pretreatment with NAC concentrationdependently inhibited BK-induced MMP-9 expression determined by gelatin zymography (Figure 1F). These results indicated that BK-induced ROS-dependent responses in RBA-1 cells, are similar to those of either animal model or rat primary cultured astrocytes. Thus, the following experiments were performed using RBA-1 cells throughout this study.

\section{Nox2-derived ROS generation contributes to BK-induced MMP-9 expression}

The NADPH oxidase (Nox) is considered to be a major source of ROS in several physiological and pathological processes $[8,24]$. To explore whether Nox is involved in BK-induced MMP-9 expression, as shown in Figure 2A, B, BK-induced MMP-9 protein and mRNA expression was attenuated by pretreatment with a Nox inhibitor diphenyleneiodonium (DPI, $1 \mu \mathrm{M}$ ). To further investigate whether BK stimulates Nox activity, as shown in Figure 2C, BK time-dependently stimulated Nox activity which was attenuated by pretreatment with DPI $(1 \mu \mathrm{M})$ in RBA-1 cells. To determine which Nox isoforms 


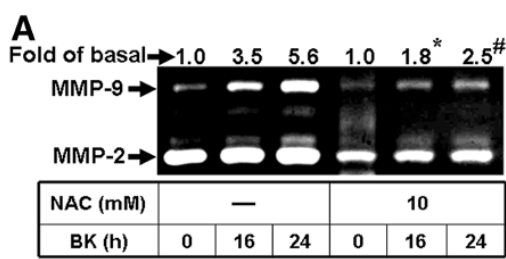

\section{C}

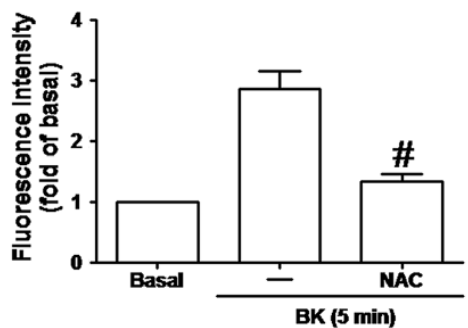

E

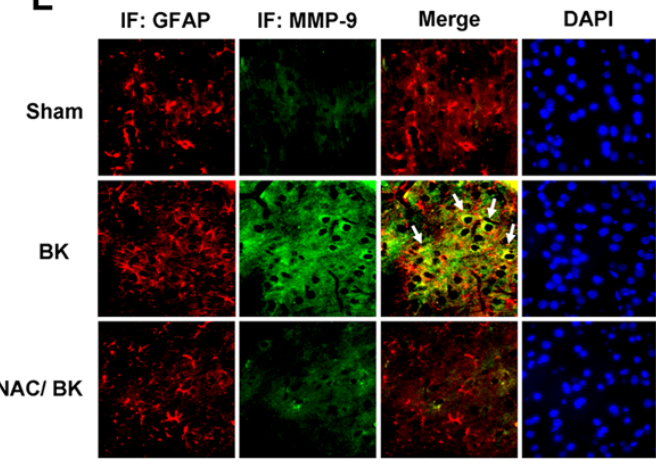

$\mathbf{F}$

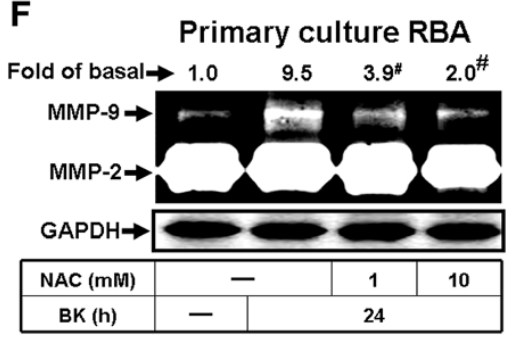

B

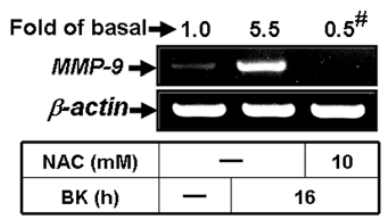

D
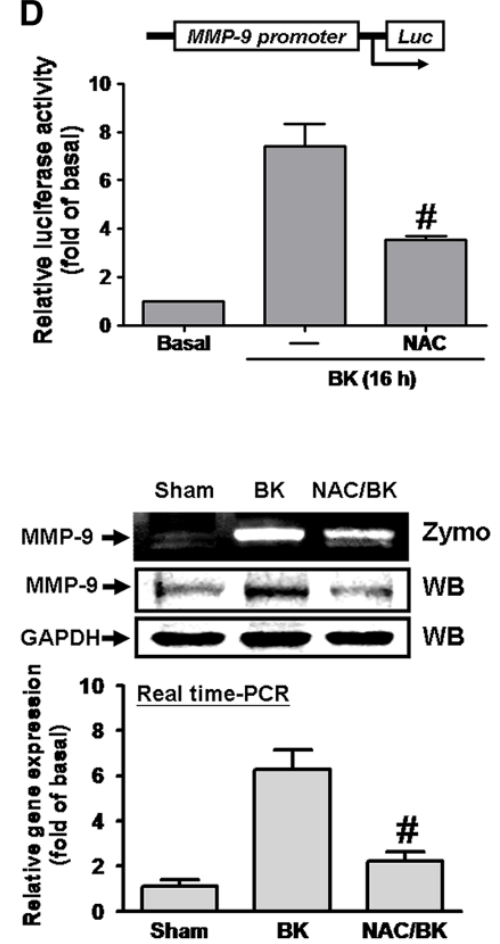

Figure 1 ROS is a fundamental element during BK-induced MMP-9 expression in RBA-1 cells. (A) Cells were pretreated without or with $\mathrm{N}$-acetylcysteine (NAC, $10 \mathrm{mM}$ ) for $1 \mathrm{~h}$ before exposure to $10 \mathrm{nM}$ BK for $24 \mathrm{~h}$. The conditioned media were collected for zymographic analysis of MMP-9 expression and activity. (B) Cells were pretreated with or without NAC for $1 \mathrm{~h}$ before exposure to BK for $16 \mathrm{~h}$. The total RNA was collected and analyzed by RT-PCR. (C) Cells were incubated with the DCF-DA $(5 \mu \mathrm{M})$ for $45 \mathrm{~min}$, followed by stimulation with $10 \mathrm{nM}$ BK for 5 min in presence or absence of NAC. The fluorescence intensity of cells was determined. (D) Cells were transiently cotransfected with $0.9 \mu \mathrm{g}$ of PGL-MMP9-Luc and $0.1 \mathrm{\mu g}$ of pGal coding for $\beta$-galactosidase for overnight. Cells were treated with BK for $16 \mathrm{~h}$ in the absence or presence of NAC (10 mM) for $1 \mathrm{~h}$ before being harvested for measuring the luciferase and $\beta$-galactosidase activities. (E) Immunofluorescence staining for MMP-9 or GFAP in serial sections of the brain cortex tissue from vehicle-treated rat (Sham), BK-injected rat (BK), or NAC-pretreated rat (NAC/BK). The arrow indicates GFAP-positive cells overlapping with MMP-9 expression. DAPI was used to stain the nucleus. Image of fluorescence microscope, 400x. Similarly, the MMP-9 protein and mRNA of brain cortex tissues (Sham, BK, and NAC/BK) were analyzed by Western blot, zymography, and real-time PCR. (F) Rat primary astrocytes were isolated and cultured, and pretreated with or without NAC (1 or 10 mM) before exposure to BK for $24 \mathrm{~h}$. The conditioned media and cell lysates were collected and analyzed by zymography and Western blotting. Data are expressed as the mean \pm SEM $(n=3) .{ }^{*} P<0.05$; ${ }^{\#} P<0.01$, as compared with the respective values of cells stimulated with BK only. 


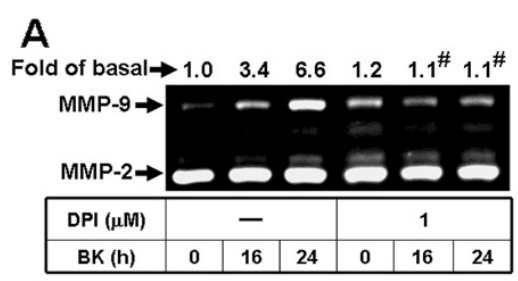

B
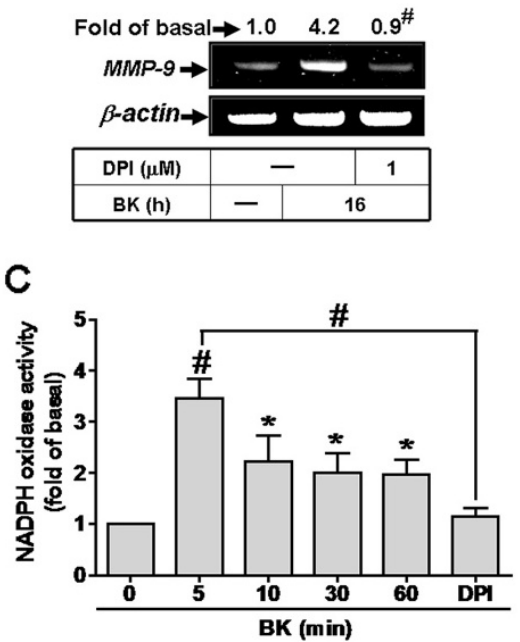

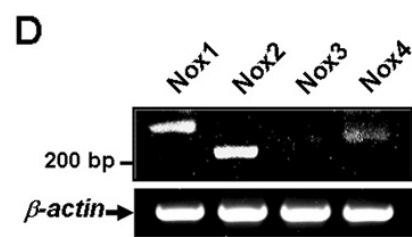

E
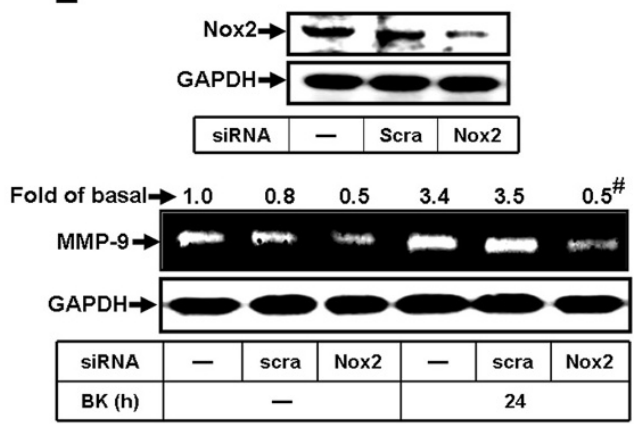

Figure 2 NADPH oxidase-dependent ROS generation is involved in BK-induced MMP-9 expression in RBA-1 cells. (A) Cells were pretreated without or with DPI $(1 \mu \mathrm{M})$ for $1 \mathrm{~h}$ before exposure to $10 \mathrm{nM}$ BK for the indicated time intervals. The conditioned media were collected for zymographic analysis of MMP-9 expression. (B) Cells were pretreated with or without DPI (1 $\mu \mathrm{M})$ for $1 \mathrm{~h}$ before exposure to $10 \mathrm{nM}$ BK for $16 \mathrm{~h}$. The total RNA was collected and analyzed by RT-PCR. (C) Cells were pretreated without or with DPI (1 $\mu \mathrm{M})$ for $1 \mathrm{~h}$ and then incubated with $10 \mathrm{nM}$ BK for the indicated time intervals or $5 \mathrm{~min}$. The Nox activity was analyzed. (D) The total RNA was collected and analyzed Nox isotypes expression by RT-PCR. (E) Cells were transfected with scramble (scra) or Nox2 siRNA for 24 h, followed by incubation with 10 nM BK for $24 \mathrm{~h}$. The conditioned media and cell lysates were collected for zymography of MMP-9 or Western blotting to determine the levels of Nox2 and GAPDH (as an internal control). Data are expressed as the mean \pm SEM $(n=3)$. ${ }^{*} P<0.05$; ${ }^{\#} P<0.01$, as compared with the respective values of cells stimulated with vehicle $(\mathbf{C})$ and BK $(\mathbf{A}-\mathbf{C}, \mathbf{E})$ only. The figure represents one of three similar experiments.

involved in these responses, the expression of Nox isoforms was analyzed by RT-PCR. The data showed that Nox1, Nox2, and Nox4 were expressed in RBA-1 cells and Nox2 predominantly expressed in comparison with those of Nox1 and Nox4 mRNA levels (Figure 2D). Next, the involvement of Nox2 in BK-induced responses was confirmed by transfection with Nox2 siRNA. As shown in Figure 2E, transfection of cells with Nox2 siRNA knocked down Nox2 protein expression and attenuated BK-induced MMP-9 expression in RBA-1 cells. These results suggested that BK-induced MMP-9 expression is mediated through $\operatorname{Nox}(2)$-dependent ROS generation in RBA-1 cells.

\section{Involvement of $\mathrm{p} 47^{\text {phox }} /$ Nox2-dependent ROS generation in BK-induced MMP-9 expression}

Nox is a multimeric protein complex consisting of at least three cytosolic subunits of $\mathrm{p} 47^{\text {phox }}, \mathrm{p} 67^{\text {phox }}$, and $\mathrm{p} 40^{\mathrm{phox}} \cdot \mathrm{p} 47^{\mathrm{phox}}$ has been shown to organize the translocation of other cytosolic factors, hence its designation as "organizer" [25]. Here, to investigate the role of $\mathrm{p} 47^{\text {phox }}$ in BK-induced MMP-9 expression, a $\mathrm{p} 47^{\text {phox }}$ subunit inhibitor apocynin (Apo) was used. The results showed that pretreatment with Apo $(10 \mu \mathrm{M})$ attenuated BK-induced MMP-9 protein and mRNA expression (Figure 3A, B). We next determined whether the translocation of $\mathrm{p} 47^{\text {phox }}$ involved in $\mathrm{BK}$-induced responses, as shown in Figure $3 \mathrm{C}$, BK stimulated translocation of $\mathrm{p} 47^{\text {phox }}$ from the cytosol to the membrane with a maximal response within $3 \mathrm{~min}$, which was attenuated by pretreatment with Apo. These results were further supported by the data of immunofluorescence images using a fluorescent microscope (Figure 3C). To ascertain that $\mathrm{p} 47^{\text {phox }}$ is essential for BK-stimulated Nox-dependent ROS generation, the Nox activity and ROS generation were detected. As shown in Figure 3D, pretreatment with Apo $(10 \mu \mathrm{M})$ inhibited the BK-stimulated Nox activation and ROS generation (Figure 3D). To further ensure the effect of $\mathrm{p} 47^{\text {phox }}$ on BK-induced MMP-9 expression, as shown in Figure $3 \mathrm{E}$, transfection with 
A

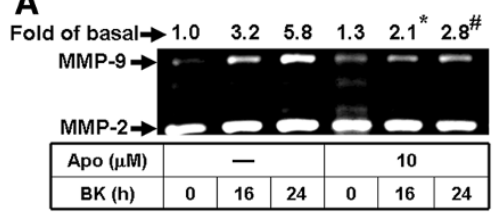

B

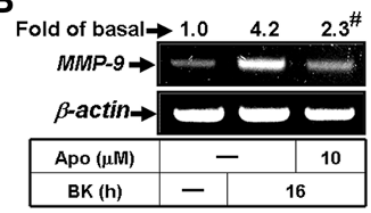

C
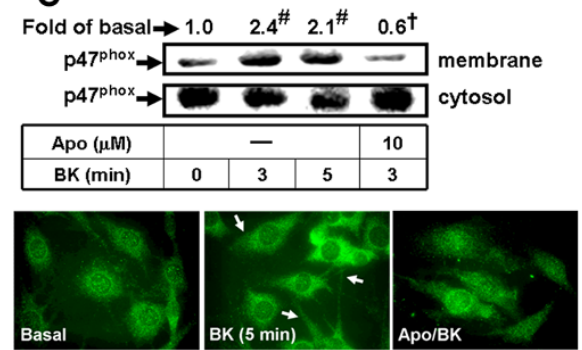

D

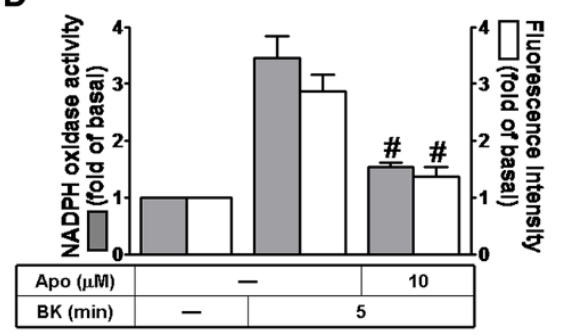

E
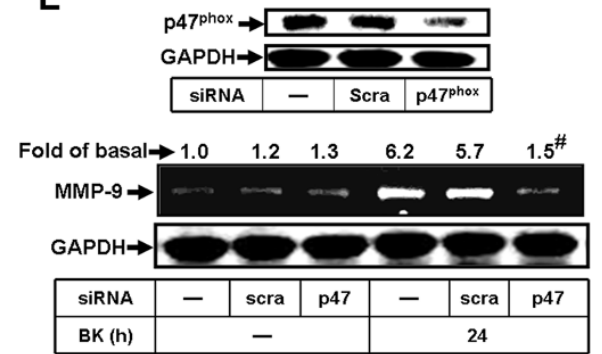

Figure 3 BK induces MMP-9 expression via p47 ${ }^{\text {phox }}$ translocation in RBA-1 cells. (A) Cells were pretreated without or with Apocynin (Apo, $10 \mathrm{\mu M}$ ) for $1 \mathrm{~h}$ before exposure to $10 \mathrm{nM} \mathrm{BK}$ for the indicated time intervals. The conditioned media were collected for zymographic analysis of MMP-9 expression. (B) Cells were pretreated with or without Apo $(10 \mu \mathrm{M})$ for $1 \mathrm{~h}$ before exposure to $10 \mathrm{nM}$ BK for $16 \mathrm{~h}$. The total RNA was collected and analyzed by RT-PCR. (C) Cells were pretreated without or with Apo $(10 \mu \mathrm{M})$ for $1 \mathrm{~h}$ treated with $10 \mathrm{nM}$ BK for the indicated time intervals or $3 \mathrm{~min}$. The membrane and cytosol fractions were prepared and analyzed by Western blotting. The p47 ${ }^{\text {phox }}$ translocation was also confirmed by immunofluorescent staining. (D) Cells were pretreated without or with Apo (10 $\mu \mathrm{M})$ for $1 \mathrm{~h}$ before exposure to $10 \mathrm{nM}$ BK for 5 min. The Nox activity and ROS generation were analyzed. (E) Cells were transfected with scramble (scra) or p47 ${ }^{\text {phox }}$ siRNA for $24 \mathrm{~h}$, followed by incubation with $10 \mathrm{nM}$ BK for $24 \mathrm{~h}$. The conditioned media and cell lysates were collected for zymography of MMP-9 or Western blotting to determine the levels of Nox2 and GAPDH (as an internal control). Data are expressed as the mean \pm SEM $(n=3) .{ }^{*} P<0.05$; ${ }^{\#} P<0.01$, as compared with the respective values of cells stimulated with vehicle $(\mathbf{C})$ and $\mathrm{BK}(\mathbf{A}, \mathbf{B}, \mathbf{D}, \mathbf{E})$ only. The figure represents one of three similar experiments.

p $47^{\text {phox }}$ siRNA significantly knocked down $\mathrm{p} 47^{\text {phox }}$ protein expression and blocked BK-induced MMP-9 expression. These results suggested that $\mathrm{p} 47^{\mathrm{phox}} /$ Noxdependent ROS generation plays a crucial role in BK-induced MMP-9 expression in RBA-1 cells.

\section{Role of $\mathrm{Ca}^{2+}$ in BK-induced ROS generation and MMP-9 expression}

Induction of MMP-9 by several stimuli is mediated through $\mathrm{Ca}^{2+}$-dependent pathways $[21,26]$. Therefore, to investigate whether intracellular $\mathrm{Ca}^{2+}$ change involves in BK-induced responses, an intracellular $\mathrm{Ca}^{2+}$ chelator (BAPTA/AM) and an ER $\mathrm{Ca}^{2+}$-ATPase blocker (thapsigargin, TG) were used. Pretreatment with either BAPTA/AM $(30 \mu \mathrm{M})$ or TG $(1 \mu \mathrm{M})$ markedly attenuated BK-induced MMP-9 protein and mRNA expression (Figure 4A, B). Next, to determine the role of intracellular $\mathrm{Ca}^{2+}$ increase in $\mathrm{BK}$-induced responses, an intracellular $\mathrm{Ca}^{2+}$ indicator Fura-2/AM was used. As shown in Figure $4 \mathrm{C}$, BK stimulated a rapid increase in intracellular $\mathrm{Ca}^{2+}$ under normal buffer (solid line). To differentiate
$\mathrm{Ca}^{2+}$ release from intracellular stores or $\mathrm{Ca}^{2+}$ influx from the extracellular fluid, the same experiments were performed under $\mathrm{Ca}^{2+}$-free buffer. The data showed that BK also stimulated an intracellular $\mathrm{Ca}^{2+}$ increase under $\mathrm{Ca}^{2+}$-free condition, but smaller than those of normal buffer, which was attenuated by pretreatment with $1 \mu \mathrm{M}$ TG (Figure 4C, lower panel), suggesting that BK stimulates intracellular $\mathrm{Ca}^{2+}$ increase via TG-sensitive intracellular $\mathrm{Ca}^{2+}$ stores and extracellular $\mathrm{Ca}^{2+}$ influx. We also determined the interplay between $\mathrm{Ca}^{2+}$ and Nox/ROS generation in BK-induced MMP-9 expression. The data showed that pretreatment with either Apo $(10 \mu \mathrm{M})$ or DPI $(1 \mu \mathrm{M})$ had no effect on BK-stimulated intracellular $\mathrm{Ca}^{2+}$ increase (Figure $4 \mathrm{C}$, lower panel). In contrast, pretreatment with either BAPTA/AM $(30 \mu \mathrm{M})$ or TG $(1 \mu \mathrm{M})$ significantly attenuated BK-stimulated Nox activity and ROS generation (Figure 4D). These results indicated that intracellular $\mathrm{Ca}^{2+}$ increase is essential for BKinduced Nox/ROS-dependent MMP-9 expression in RBA-1 cells. 

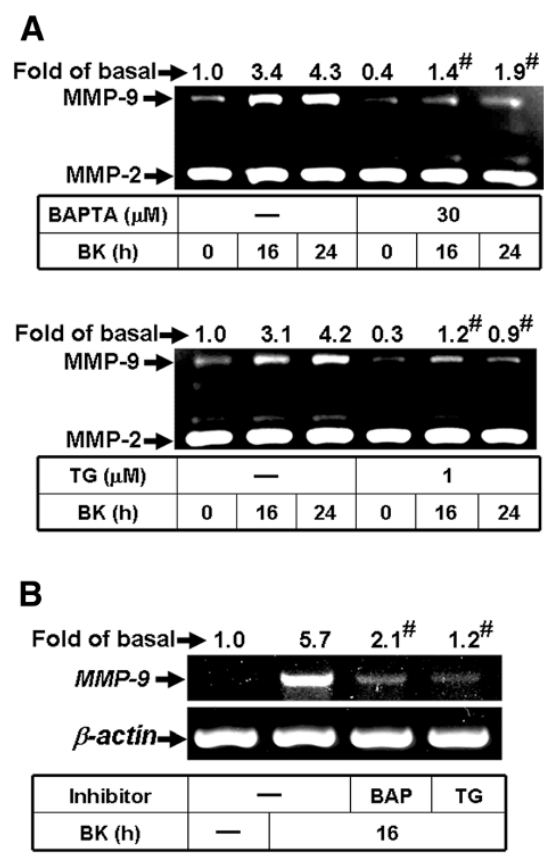

C
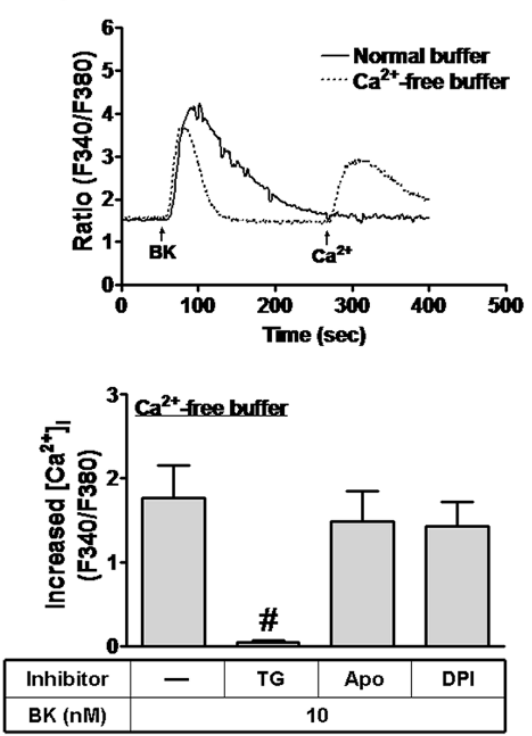

D

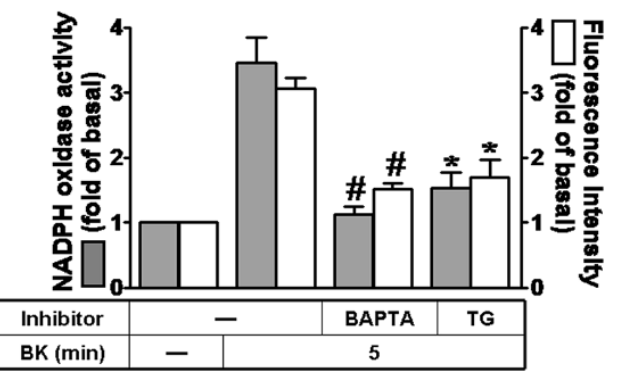

Figure 4 BK-induced $\mathrm{Ca}^{2+}$ release from internal TG-sensitive $\mathrm{Ca}^{2+}$ store plays a role in BK-induced MMP-9 expression. (A) Cells were pretreated without or with BAPTA/AM $(30 \mu \mathrm{M})$ or TG $(1 \mu \mathrm{M})$ for $1 \mathrm{~h}$ before exposure to $10 \mathrm{nM}$ BK for the indicated time intervals. The conditioned media were collected for zymographic analysis of MMP-9 expression. (B) Cells were pretreated with or without BAPTA/AM (30 $\mu M$ ) or TG $(1 \mu \mathrm{M})$ for $1 \mathrm{~h}$ before exposure to $10 \mathrm{nM}$ BK for $16 \mathrm{~h}$. The total RNA was collected and analyzed by RT-PCR. (C) For Ca ${ }^{2+}$ mobilization, confluent cultures of RBA-1 cells on glass coverslips were loaded with Fura-2/AM and fluorescent measurement of $\left[\mathrm{Ca}^{2+}\right]_{\mathrm{i}}$ was carried out in a dual excitation wavelength spectrofluorometer, with excitation at $340 \mathrm{~nm}$ and $380 \mathrm{~nm}$. Cells were incubated in $\mathrm{Ca}^{2+}$-containing normal buffer (solid line) or $\mathrm{Ca}^{2+}$-free buffer (dot line) and then exposed to BK at $50 \mathrm{sec}$. In a $\mathrm{Ca}^{2+}$-free buffer, cells were pretreated with or without TG (1 $\left.\mu \mathrm{M}\right)$, Apo $(10 \mu \mathrm{M})$, or DPI $(1 \mu \mathrm{M})$ for $30 \mathrm{~min}$, exposed to BK at $50 \mathrm{sec}$, and then $2 \mathrm{mM} \mathrm{Ca}^{2+}$ was added to the cells. (D) RBA-1 cells were pretreated without or with BAPTA/AM $(30 \mu \mathrm{M})$ or TG $(1 \mu \mathrm{M})$ for $1 \mathrm{~h}$ and then incubated with $10 \mathrm{nM}$ BK for $5 \mathrm{~min}$. The Nox activity and ROS generation were analyzed. Data are expressed as the mean $\pm \operatorname{SEM}(n=3) .{ }^{*} P<0.05 ;{ }^{\#} P<0.01$, as compared with the respective values of cells stimulated with BK only. The figure represents one of three similar experiments.

\section{BK induces MMP-9 expression via a $\mathrm{Ca}^{2+}$-dependent PKC-a manner}

PKC isoforms such as PKC- $\alpha$ have been shown to regulate MMP-9 expression in various cell types [27]. Our recent report also suggested that BK-stimulated Nox/ ROS signaling might be mediated through PKC [16]. Thus, to investigate which PKC isoforms are involved in BK-induced resposnes, pretreatment with either a panPKC inhibitor GF109203X (30 $\mu \mathrm{M})$ or a selective PKC- $\alpha$ inhibitor Gö6976 (1 $\mu \mathrm{M})$ attenuated BK-induced MMP9 expression (Figure $5 \mathrm{~A}, \mathrm{~B}$ ), suggesting that $\mathrm{PKC}(\alpha)$ is involved in BK-induced MMP-9 expression in RBA-1 cells. Moreover, the activation of PKC- $\alpha$ in BK-induced responses was further confirmed by determining its translocation from the cytosol to the membrane. As shown in Figure 5C, BK stimulated PKC- $\alpha$ translocation in a time-dependent manner with a maximal response within 5 min (Figure 5C, upper part), which was attenuated by pretreatment with either BAPTA/AM $(30 \mu \mathrm{M})$ or Gö6976 (1 $\mu \mathrm{M})$ (Figure $5 \mathrm{C}$, lower part). We further examined the role of PKC- $\alpha$ in BK-stimulated Noxderived ROS generation, pretreatment with GF109203X or Gö6976 attenuated the BK-stimulated Nox activation and ROS generation (Figure 5D), suggesting that $\mathrm{PKC}(\alpha)$ is involved in these responses. To further ensure the role of PKC- $\alpha$ in MMP-9 expression, as shown in Figure 5E, 


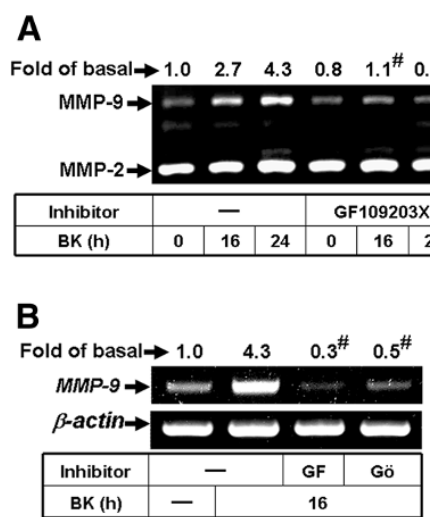

C
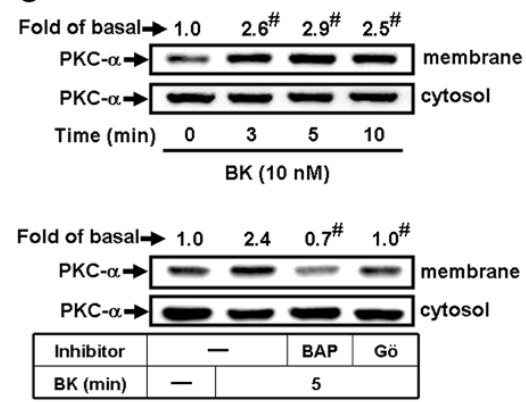

D

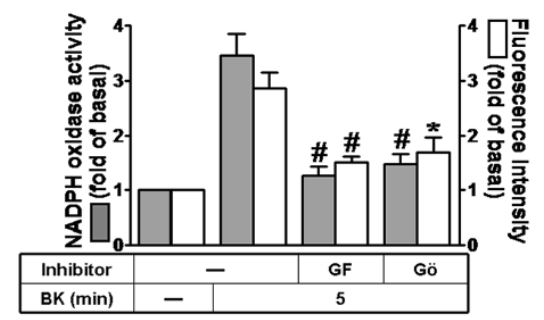

E

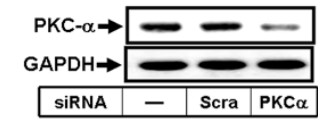

SiRNA

Fold of basal $\rightarrow 1.0 \quad 0.7 \quad 0.1 \quad 4.3 \quad 3.8 \quad 2.0^{\#}$

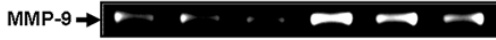

$\mathrm{GAPDH} \rightarrow \longrightarrow$

\begin{tabular}{|l|c|c|c|c|c|c|}
\hline siRNA & - & scra & PKC $\alpha$ & - & scra & PKC $\alpha$ \\
\hline BK (h) & \multicolumn{3}{|c|}{-} & \multicolumn{4}{|c|}{24} \\
\hline
\end{tabular}

$\mathbf{F}$

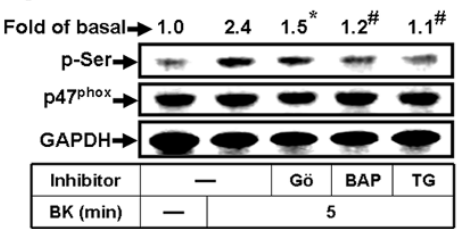

Figure 5 Involvement of PKC- $a$ in BK-induced ROS generation and MMP-9 expression in RBA-1. (A) Cells were pretreated without or with

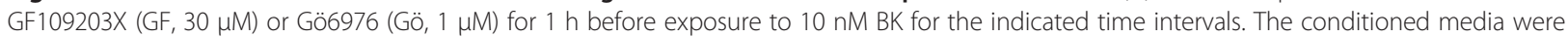
collected for zymographic analysis of MMP-9 expression. (B) Cells were pretreated with or without GF109203X (GF, $30 \mu \mathrm{M})$ or Gö6976 (Gö, 1 HM) for $1 \mathrm{~h}$ before exposure to $10 \mathrm{nM}$ BK for $16 \mathrm{~h}$. The total RNA was collected and analyzed by RT-PCR. (C) Cells were pretreated with or without BAPTA (BAP, $30 \mu \mathrm{M})$ or Gö $(1 \mu \mathrm{M})$ for $1 \mathrm{~h}$ and then treated with $10 \mathrm{nM}$ BK for the indicated time intervals (upper part) or $5 \mathrm{~min}$ (lower part). The membrane and cytosol fractions were prepared and analyzed by Western blotting. (D) Cells were pretreated without or with GF or Gö for $1 \mathrm{~h}$ before exposure to $10 \mathrm{nM}$ BK for $5 \mathrm{~min}$. The Nox activity and ROS generation were analyzed. (E) Cells were transfected with scramble (scra) or PKC-a siRNA for $24 \mathrm{~h}$, followed by incubation with $10 \mathrm{nM}$ BK for $24 \mathrm{~h}$. The conditioned media and cell lysates were collected and analyzed by zymography or Western blotting. (F) Cells were pretreated without or with Gö $(1 \mu \mathrm{M})$, BAPTA (30 $\mu \mathrm{M})$, or TG $(1 \mu \mathrm{M})$ for 1 h before exposure to 10 nM BK for 5 min. The cell lysates were collected and analyzed by Western blotting using an anti-phospho-serine (p-Ser), p47 ${ }^{\text {phox }}$, or GAPDH antibody. Data are expressed as the mean \pm SEM $(n=3) .{ }^{*} P<0.05 ;{ }^{\#} P<0.01$, as compared with the respective values of cells stimulated with vehicle $(\mathbf{C})$ and $B K(\mathbf{A}, \mathbf{B}, \mathbf{D}-\mathbf{F})$ only. The figure represents one of three similar experiments.

ttransfection with PKC- $\alpha$ siRNA knocked down PKC- $\alpha$ protein expression and attenuated BK-induced MMP-9 expression. To determine whether PKC- $\alpha$ is an upstream molecule of $\mathrm{p} 47^{\text {phox }}$ activation, as shown in Figure $5 \mathrm{~F}$, pretreatment with Gö6976 (1 $\mu \mathrm{M})$ significantly attenuated BK-stimulated phosphorylation of $\mathrm{p} 47^{\text {phox }}$ at serine residues. Moreover, pretreatment with either BAPTA/ AM $(30 \mu \mathrm{M})$ or TG $(1 \mu \mathrm{M})$ also attenuated phosphorylation of $\mathrm{p} 47^{\text {phox }}$ (Figure 5F). These results demonstrated that PKC- $\alpha$ contributes to BK-induced Nox (p47 $\left.{ }^{\text {phox }}\right) /$ ROS generation and MMP-9 expression in RBA-1 cells.

\section{Activation of AP-1 is required for BK-induced MMP-9 expression}

AP-1-dependent pathway has been shown to involve in MMP-9 expression in various cell types [22]. To determine whether AP-1 is required for MMP-9 induction by
$\mathrm{BK}$, an AP-1 inhibitor (tanshinone IIA) was used. As shown in Figure 6A, BK-induced MMP-9 expression was attenuated by pretreatment with tanshinone IIA (TSIIA, $10 \mu \mathrm{M})$. The expression and nuclear accumulation of AP-1 serve as an indicator of downstream gene activation [28]. Thus, we examined whether BK stimulates nuclear accumulation of AP-1 (i.e. c-Fos and c-Jun) in RBA-1 cells. First, we found that BK stimulated an accumulation of c-Fos and c-Jun (phospho-c-Jun) in nucleus within $30 \mathrm{~min}$, which was blocked by BAPTA/AM $(30 \mu \mathrm{M})$, Gö6976 $(1 \mu \mathrm{M})$, apocynin $(10 \mu \mathrm{M})$, DPI $(1 \mu \mathrm{M})$, or NAC (10 mM) (Figure 6B). To determine whether BK enhanced AP-1 transcriptional activity, a promoter containing AP-1 binding sites reporter construct was used. The data showed that BK stimulated an increase in AP-1 promoter activity which was significantly inhibited by pretreatment with BAPTA/AM $(30 \mu \mathrm{M})$, TG $(1 \mu \mathrm{M})$, 
A

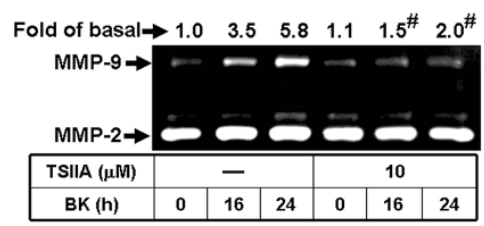

B

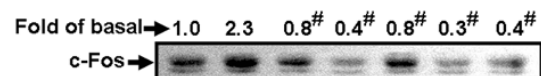

Fold of basal $\rightarrow 1.0 \quad 3.3 \quad 1.2^{\#} \quad 1.6^{\#} \quad 1.4^{\#} \quad 1.3^{\#} 1.1^{\#}$ $\mathrm{p}$-c-Jun $\rightarrow--\infty-\infty-$

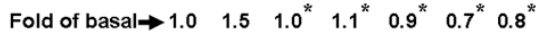
c.Jun $\rightarrow-2-\infty-2$

\begin{tabular}{|l|c|c|c|c|c|c|}
\hline Inhibitor & \multicolumn{1}{|c|}{$\begin{array}{c}\text { 30 } \\
\text { BK (min) }\end{array}-$} & \multicolumn{7}{|c|}{ BAP } & Gö & Apo & DPI & NAC \\
\hline
\end{tabular}

C

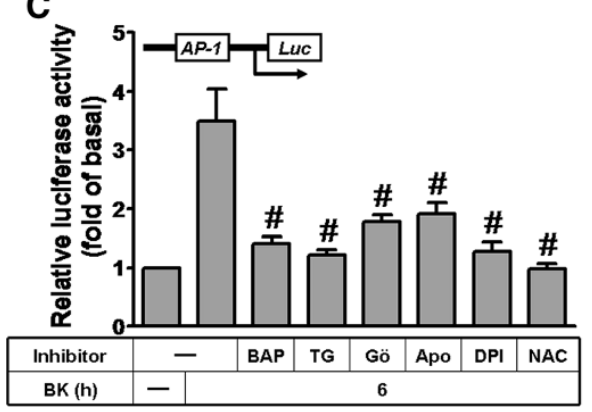

D

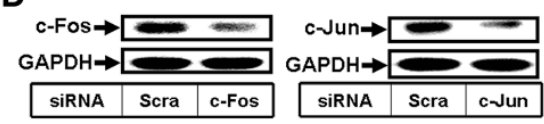

Fold of basal $\rightarrow 1.0 \quad 2.3 \quad 1.0 \quad 2.4 \quad 0.2 \quad 0.3^{\#} \quad 0.6 \quad 0.6^{\#}$

MMP-9 $\rightarrow=-\infty \quad m-\infty \cdots \cdots$

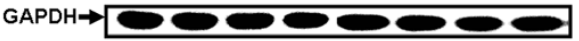

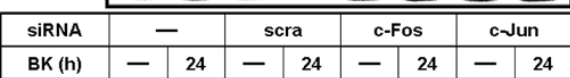

Figure 6 AP-1 (c-Fos/c-Jun) is essential for BK-induced MMP-9 expression through a Ca ${ }^{2+} /$ PKC-a/Nox2/ROS cascade. (A) Cells were pretreated without or with tanshinone IIA (TSIIA, $10 \mu \mathrm{M})$ for $1 \mathrm{~h}$ before exposure to $10 \mathrm{nM}$ BK for the indicated time intervals. The conditioned media were collected for zymographic analysis of MMP-9 expression. (B) Cells were pretreated without or with BAPTA (BAP, 30 M), Gö6976 (Gö, $1 \mu \mathrm{M})$, Apo $(10 \mu \mathrm{M})$, DPI $(1 \mu \mathrm{M})$, or NAC $(10 \mathrm{mM})$ for $1 \mathrm{~h}$ before exposure to $10 \mathrm{nM}$ BK for $30 \mathrm{~min}$. The nuclear fraction was collected and analyzed by Western blotting using an anti-c-Fos, phospho-c-Jun, or c-Jun antibody. (C) Cells were transiently cotransfected with pAP1-Luc and pGal for $24 \mathrm{~h}$, pretreated with BAPTA (BAP), TG, Gö, Apo, DPI, or NAC for $1 \mathrm{~h}$ and then incubated with BK for $6 \mathrm{~h}$. The AP-1 promoter activity in the cell lysates was determined. (D) Cells were transfected with scramble (scra) or c-Fos/c-Jun siRNA for 24 h, followed by incubation with $10 \mathrm{nM}$ BK for $24 \mathrm{~h}$. The conditioned media and cell lysates were collected and analyzed by zymography or Western blotting. Data are expressed as the mean \pm SEM $(n=3) .{ }^{*} P<0.05 ;{ }^{\#} P<0.01$, as compared with the respective values of cells stimulated with BK only. The figure represents one of three similar experiments.

Gö6976 $(1 \mu \mathrm{M})$, Apo $(10 \mu \mathrm{M})$, DPI $(1 \mu \mathrm{M})$, or NAC $(10 \mathrm{mM})$ (Figure $6 \mathrm{C})$. To further confirm the role of AP1 in BK-induced MMP-9 expression, cells were transfected with c-Fos or c-Jun siRNA. The results showed that transfection with c-Fos or c-Jun siRNA significantly knocked down respective c-Fos or c-Jun proteins and attenuated BK-induced MMP-9 expression (Figure 6D). These results suggested that BK stimulates AP-1 (i.e. c-Fos and c-Jun) activation via the PKC- $\alpha$-dependent Nox2/ROS generation, which is essential for up-regulation of MMP-9 in RBA-1 cells.

\section{BK enhances recruitment of AP-1 to MMP-9 promoter and} astrocytic migration

MMP-9 promoter region contains AP-1 binding sites [29]. Hence, we used ChIP-PCR assay to determine whether BK stimulates recruitment of AP-1 to MMP-9 promoter leading to MMP-9 expression. We designed a pair of primers for MMP-9 promoter (-597 to -318) region, containing an AP-1 binding site. Chromatin was immunoprecipitated using an anti-c-Fos or anti-c-Jun antibody, and the MMP-9 promoter region (-597 to -318) was amplified by PCR. As shown in Figure 7A (upper part), BK time-dependently stimulated binding of
c-Fos and c-Jun to the MMP-9 promoter with a maximal response within $30 \mathrm{~min}$, which was attenuated by pretreatment with BAPTA/AM, Gö6976, Apo, DPI, or NAC (Figure 7A, lower part). We next examined whether BKinduced MMP-9 promoter activity is also regulated by these signaling components. We have constructed a MMP-9 promoter into a pGL3-basic vector containing the luciferase reporter system (pGL-MMP-9-Luc), which contains the AP-1 binding sites [30]. BK stimulated an increase in MMP-9 promoter activity which was attenuated by pretreatment with BAPTA/AM, Gö6976, Apo, or DPI and transfection with c-Fos or c-Jun siRNA (Figure 7B), suggesting that BK-induced MMP-9 promoter activity is mediated through PKC- $\alpha$, Nox/ROS, and AP-1 in RBA- 1 cells. To further determine the functional role of AP-1 transcription factor in BK-induced MMP-9 promoter induction, wild-type (WT) and pointmutated (mt)-AP1 MMP-9 promoter constructs (as illustrated in Figure 7C, upper part) were tested for induction by BK. As shown in Figure $7 \mathrm{C}$, BK driven MMP-9 promoter activity was totally lost in AP1 promoter mutant, thus indicating that AP-1 binding domain is required for MMP-9 promoter activation by BK in RBA-1 cells. These results confirmed that BK-increased 
A

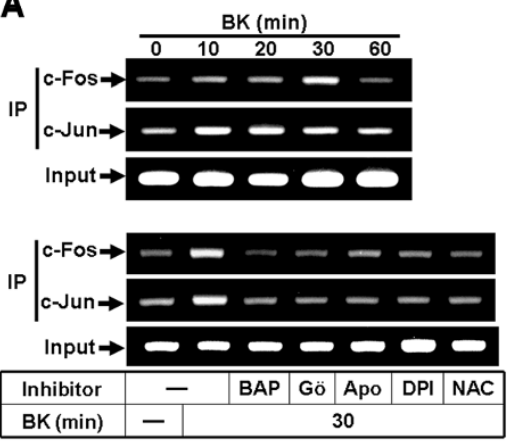

\section{C}

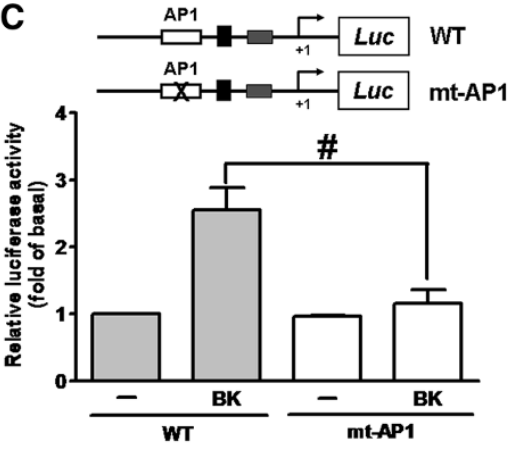

B

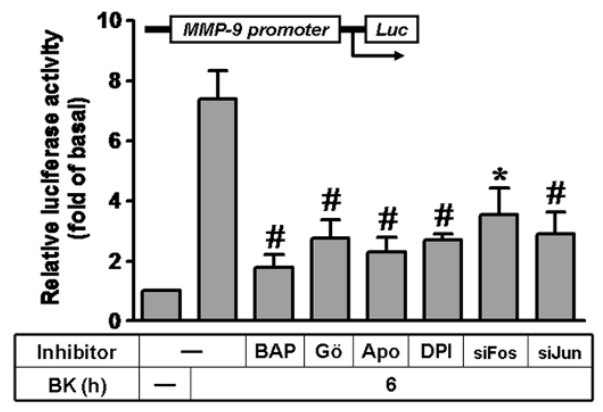

D

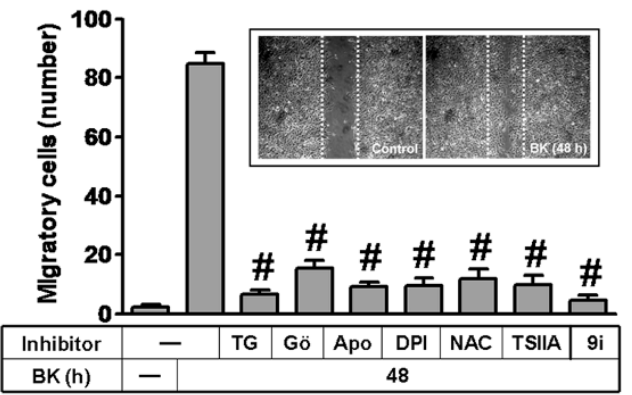

E

Primary culture RBA

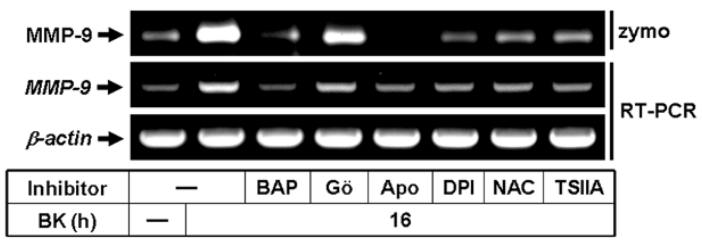

Figure 7 BK induces astrocytic migration through Nox/ROS-dependent AP-1 increasing MMP-9 gene expression. (A) Cells were

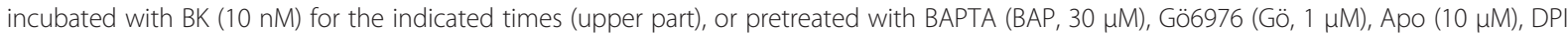
$(1 \mu \mathrm{M})$, or NAC $(10 \mathrm{mM})$ for $1 \mathrm{~h}$ and then incubated with $10 \mathrm{nM}$ BK for $30 \mathrm{~min}$. The c-Fos and c-Jun AP-1 binding activity were analyzed by chromatin-IP (ChIP)-PCR assay. (B) Cells were transiently cotransfected with pGL-MMP9-Luc and pGal for 24 h, pretreated with BAPTA (BAP), Gö, Apo, DPI, or transfection with c-Fos or c-Jun siRNA for $24 \mathrm{~h}$ and then incubated with BK for $16 \mathrm{~h}$. (C) Schematic representation of the different MMP-9-luciferase constructs, either wild-type (WT) or modified by single-point mutation of the AP-1 binding site (upper part). After cotransfection, luciferase activities of different MMP-9-promoter constructs after stimulation with or without BK (10 nM) for $16 \mathrm{~h}$, were measured as relative MMP9 promoter activity to that of $\beta$-galactosidase. (D) Cells were plated on 6-well culture plates, grew to confluence and starved with serum-free DMEM/F-12 medium for $24 \mathrm{~h}$. Cells were pretreated with TG, Gö, Apo, DPI, NAC, TSIIA, or MMP-9i (9i) for $1 \mathrm{~h}$ and the monolayer cells were manually scratched with a blue tip as described in Methods, and then incubated with BK (10 nM) for $48 \mathrm{~h}$. Phase contrast images of cells were taken at $48 \mathrm{~h}$ and the number of cell migration was counted as described in Methods. (E) Rat primary cultured astrocytes were pretreated with BAPTA (BAP), Gö, Apo, DPI, NAC, or TSIIA before exposure to BK for $16 \mathrm{~h}$. The conditioned media and total RNA were collected and analyzed by zymography and RT-PCR. Data are expressed as the mean \pm SEM $(n=3) .{ }^{\#} P<0.01$, as compared with the respective values of cells stimulated with BK only.

MMP-9 promoter activity is mediated through binding of AP-1 (c-Fos/c-Jun) to the MMP-9 promoter region.

Ultimately, to demonstrate the functional effect of upregulated MMP-9 by BK, we evaluated the cell migration of RBA-1 cells. The images of cell migration induced by BK $(10 \mathrm{nM})$ were observed and taken at $48 \mathrm{~h}$ (Figure 7D, inset panel). The number of migratory cells was counted and the statistical data were presented in Figure 7D. The data showed that pretreatment with TG
(1 $\mu \mathrm{M})$, Gö6976 (1 $\mu \mathrm{M})$, Apo $(10 \mu \mathrm{M})$, DPI $(1 \mu \mathrm{M})$, NAC $(10 \mathrm{mM})$, TSIIA $(10 \mu \mathrm{M})$, or MMP-9i $(9 \mathrm{i}, 1 \mu \mathrm{M})$ significantly blocked BK-induced cell migration, suggesting that BK-induced MMP-9 expression and cell migration is mediated through $\mathrm{Ca}^{2+} / \mathrm{PKC}-\alpha-$ dependent Nox2/ ROS and AP- 1 cascade in RBA- 1 cells.

To confirm these results in primary culture astrocytes, the rat primary cultured astrocytes were pretreated with BAPTA (BAP), Gö, Apo, DPI, NAC, or TSIIA before 
exposure to BK $(10 \mathrm{nM})$ for $16 \mathrm{~h}$. The conditioned media and total RNA were collected and analyzed by zymography and RT-PCR analysis. As shown in Figure 7E, pretreatment with BAPTA (BAP), Gö, Apo, DPI, NAC, or TSIIA significantly inhibited BK-induced MMP-9 protein and mRNA expression, suggesting that BK induced MMP-9 expression via $\mathrm{Ca}^{2+}$-dependent PKC- $\alpha$, Nox-derived ROS, and AP-1 pathways in the primary cultured astrocytes.

\section{Discussion}

MMP-9 expression and activation play a critical role in tissue remodeling associated with the pathogenesis of brain diseases [3]. Reduction of MMP activity by pharmacological inhibitors or gene knock-out strategies protects the brain from BBB disruption, cell death, and advanced neuroinflammation [2,29]. Moreover, BK and related peptides are simultaneously produced and released following brain injury [14]. The role of BK implicated in astrocytic functions is not completely understood. Thus, we investigated the molecular mechanisms underlying BK-induced MMP-9 expression in cultured RBA-1 cells and an animal model. Our results suggest that in brain astrocytes, activation of $\mathrm{Ca}^{2}$ +/PKC- $\alpha$-dependent Nox2/ROS signal leading to induction of AP-1 (c-Fos/c-Jun) is essential for BK-induced MMP-9 gene expression and enhancing cell migration. The findings suggest that BK-induced MMP-9 expression and cell migration may contribute to increase $\mathrm{BBB}$ permeability and recruit immune cells, leading to brain inflammation and edema. In addition, astrocytic migration may be involved in brain inflammation and remodeling during brain injuries such as brain wound healing, tissue remodeling, and glial scar formation $[2,3,19,20]$.

Imbalance in the level of ROS has been shown to play a causative role in numerous pathologies of degenerative diseases [23,31]. ROS concentration-dependently exert a key role in the normal physiological functions and the inflammatory responses [9]. In the brain, ROS also extend to the control of vascular tone which is tightly modulated by metabolic activity within neurons [6]. Moreover, increasing ROS generation by diverse stimuli can regulate the expression of inflammatory mediators in pathogenesis of brain disorders [24,31]. Recently, the cellular damage in neurodegenerative disorders such as Alzheimer's disease is attributed to oxidative stress $[7,10,11]$. BK-induced ROS generation has been reported in cerebral arterioles and renal diseases [13]. In this study, our data demonstrated that in both in vitro and in vivo studies, BK induces MMP-9 expression via ROSdependent pathways in brain astrocytes. Moreover, we found that BK-induced MMP-9 expression is mediated through Nox-dependent ROS generation, since pretreatment with ROS scavenger NAC or Nox activity inhibitor
DPI attenuated BK-induced responses. The involvement of Nox-dependent ROS generation in BK-induced responses was further confirmed by NAC or DPI in RBA-1 cells. ROS exert as a major signaling factor which mediates microglial activation induced by inflammatory mediators, including LPS [12]. Herein we are the first group to establish that Nox-dependent intracellular redox signal (ROS generation) contributes to MMP-9 expression induced by BK in brain astrocytes.

Moreover, Nox is considered to be a major source of ROS in several physiological and pathological processes $[8,24]$. To date, there are five isoforms of Nox have been discovered, including Nox1-5 [24]. Nox1, Nox2, and Nox4 have been shown to be expressed and are crucial for ROS generation in brain cells [8,32]. First, our data demonstrated that Nox activity is involved in BK-induced responses by a Nox inhibitor DPI (Figure 2A-C). As previous reports, we also found that RBA-1 cells express Nox1, Nox2, and Nox4 (Figure 2D). Next, BK-induced MMP-9 expression is predominantly mediated through activation of Nox2, confirmed by respective Nox siRNAs (Figure 2E). The involvement of Nox in BK-induced responses is mediated through phosphorylation and translocation of $\mathrm{p} 47^{\text {phox }}$ (a Nox2 component) which was attenuated by a $\mathrm{p} 47^{\text {phox }}$ inhibitor apocynin or $\mathrm{p} 47^{\mathrm{phox}}$ siRNA (Figure 3). These results are consistent with previous studies showing that Nox is expressed in astrocytes and contributes to ROS generation $[16,33]$ and Nox is involved in LPS-induced MMPs expression in Raw264.7 [34]. Additionally, we also demonstrated that BK-stimulated Nox2-dependent ROS signal and MMP-9 expression is mediated through $\mathrm{Ca}^{2}$ ${ }^{+}$-dependent PKC- $\alpha$ activation, confirmed by an intracellular $\mathrm{Ca}^{2+}$ chelator (BAPTA/AM), the inhibitor of ER $\mathrm{Ca}^{2+}$-ATPase (TG), pan-PKC (GF109203X), or PKC- $\alpha$ (Gö6976) and PKC- $\alpha$ siRNA (Figure 4, 5). These data demonstrated that $\mathrm{BK}$ stimulates $\mathrm{Ca}^{2+}$-dependent $\mathrm{PKC}-\alpha$ activation linking to Nox2/ROS generation and MMP-9 expression in RBA-1 cells. It is consistent with previous studies indicating that overexpression of $\mathrm{PKC}-\alpha$ can increase phosphorylation of $\mathrm{p} 47^{\text {phox }}$ and induce both its translocation and Nox activation in human neutrophils [35].

The excessive increase of oxidative stress during injuries not only causes oxidative damage to cellular macromolecules, but also modulates the pattern of gene expression through functional alterations of transcription factors. The transcription factor AP-1 is well known to be modulated during oxidative stress associated with inflammatory diseases [36]. Moreover, BK-induced gene expression has been shown to be mediated through one of transcription factors such as AP-1 [18]. However, the mechanistic connection between the MMP-9 expression and the ROS-dependent pathway induced by BK has not 
been established in RBA-1 cells. In this study, we demonstrated that AP-1 is essential for BK-induced MMP-9 expression which was inhibited by an AP-1 inhibitor TSIIA (Figure 6A). The involvement of AP-1 in BK-induced responses was further confirmed by determining induction of AP-1 (c-Fos/c-Jun), including phosphorylation of c-Jun, accumulation of c-Fos in nucleus, and AP-1 promoter reporter activity. These responses were attenuated by the $\mathrm{Ca}^{2+}$ chelator (BAPTA/AM), the inhibitor of PKC- $\alpha$ (Gö6976), p47 $7^{\text {phox }}$ (apocynin), Nox (DPI), or a ROS scavenger (NAC), suggesting that the $\mathrm{Ca}^{2+} / \mathrm{PKC}-\alpha / \mathrm{p} 47^{\text {phox }} / \mathrm{Nox} / \mathrm{ROS}$ cascade is involved in activation of AP-1 which contributes to BK-induced MMP-9 expression in RBA-1 cells. Moreover, the role of AP-1 in BK-induced MMP-9 expression was also confirmed by either c-Fos or c-Jun siRNA to inhibit BKinduced MMP-9 expression. These results are consistent with the involvement of AP-1 in MMP-9 expression induced by ox-LDL and LTA in RBA-1 cells [21,22].

To confirm AP-1 indeed binds to the promoter region of MMP-9 gene, the binding activity of AP-1 was determined by a ChIP-PCR assay. In this study, BK stimulated AP-1 (c-Fos and c-Jun) recruitment and activation via $\mathrm{Ca}^{2+} / \mathrm{PKC}-\alpha$-dependent Nox/ROS cascade and enhancing MMP-9 promoter activity. We further confirmed that AP-1 binding site (-503 to -497$)$ within MMP-9 promoter is required for BK-induced MMP-9 transcriptional activity by using an AP-1-mutated MMP-9 promoter construct. These results demonstrated that activation of AP-1 (either c-Fos or c-Jun) is essential for BK-induced MMP-9 gene expression which is mediated through a $\mathrm{Ca}^{2+} / \mathrm{PKC}-\alpha$-dependent Nox/ROS signal in RBA-1 cells. It is consistent with previous studies showing that AP-1 is involved in MMP-9 expression in various cell types [22,37].

Several reports have shown the multiple effects of BK and MMP-9 on brain glial cells [30,38]. In brain injury, up-regulation of BK, ROS, and MMP-9 may increase BBB permeability, recruit immune cells infiltrating through BBB into the tissues, and subsequently result in brain inflammation and edema [38]. In this study, we suggested that BK-induced Nox2-mediated ROS signal, MMP-9 expression, and astrocytic migration might be involved in brain inflammation and remodeling during brain injuries. Both ROS [39] and MMP-9 [37] have been reported to play a critical role in cell motility in several cell types. Herein we demonstrated that BK induces MMP-9 expression and cell migration via PKC$\alpha$-dependent Nox/ROS signaling pathway in RBA-1 cells. The results are consistent with recent reports indicating that the ROS-dependent MMP-9 expression is essential for cell migration by various stimuli such as TGF- $\beta 1$ or LPS [20,34]. Hence, we suggest that ROS-mediated MMP-9 up-regulation by BK is associated with cell migration in RBA-1 cells. Taken together, BK, ROS, and MMP-9 may have multiple effects on different types of brain glial cells, inducing inflammatory and remodeling roles.

\section{Conclusions}

We have demonstrated that BK directly induces MMP-9 expression via $\mathrm{Ca}^{2+}$-dependent PKC- $\alpha, \mathrm{p} 47^{\text {phox }} / \mathrm{Nox} 2$ mediated ROS generation, linking to activation of AP-1 (c-Fos/c-Jun), which results in the cell migration in RBA-1 cells. Based on the observations from literatures and our findings, Figure 8 depicts a model for the molecular mechanisms underlying BK-induced MMP-9 expression and functional changes (e.g. migration) in RBA-1 cells. These findings concerning BK-induced Nox-dependent redox signal and MMP-9 up-regulation in brain astrocytes imply that BK-mediated ROS signals might play a critical role in the modulation of brain injuries and inflammatory diseases.

\section{Methods}

\section{Materials}

Dulbecco's modified Eagle's medium (DMEM)/Ham's nutrient mixture F-12 (F-12), fetal bovine serum (FBS), and PKC- $\alpha, \mathrm{p} 47^{\text {phox }}$, Nox 2 , c-Fos and c-Jun siRNAs were purchased from Invitrogen (Carlsbad, CA). Hybond $\mathrm{C}$ membrane and enhanced chemiluminescence (ECL) detection system were from GE Healthcare Biosciences (Buckinghamshire, UK). MMP-9 antibody was from NeoMarker (Fremont, CA). PKC- $\alpha, \mathrm{p} 47^{\text {phox }}$, Nox1, Nox2, Nox4, phospho-c-Jun, c-Fos, and c-Jun antibodies were from Santa Cruz (Santa Cruz, CA). All primary

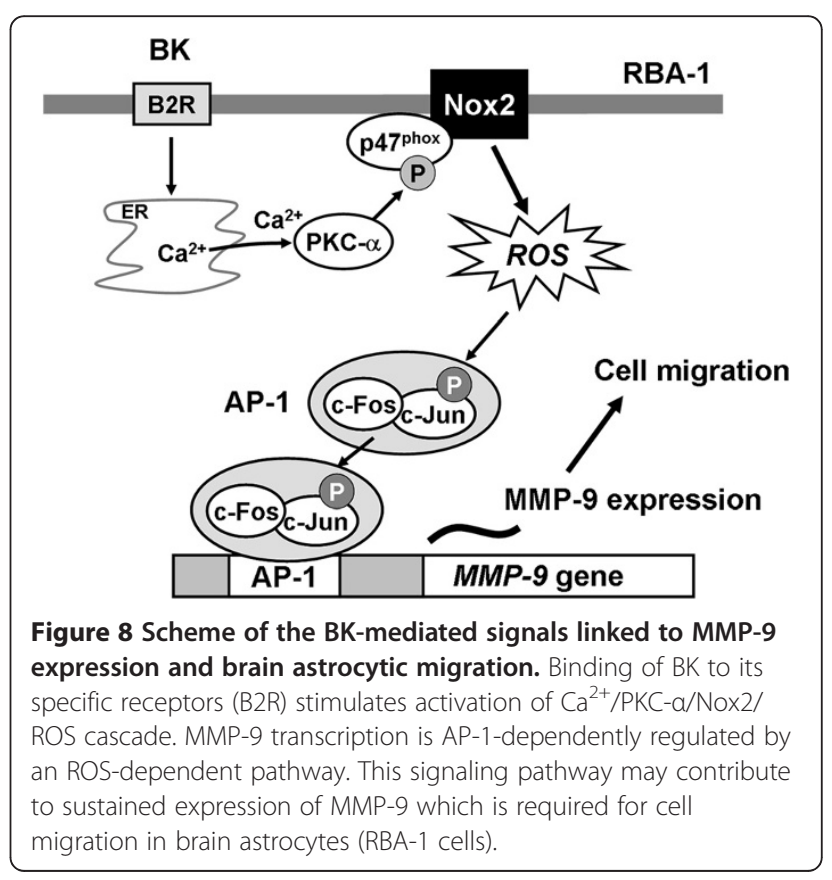


antibodies were diluted at 1:1000 in PBS with 1\% BSA. BAPTA/AM, thapsigargin, GF109203X, Gö6976, apocynin, diphenyleneiodonium chloride (DPI), and tanshinone IIA (TSIIA) were from Biomol (Plymouth Meeting, $\mathrm{PA})$. Bicinchoninic acid (BCA) protein assay reagent was from Pierce (Rockford, IL). BK, N-acetyl cysteine (NAC), enzymes, and other chemicals were from Sigma (St. Louis, MO).

\section{Cell cultures and treatment}

The RBA-1 originated from a primary cultured astrocyte of neonatal rat cerebrum and was naturally developed through successive cell passages [30] and used throughout this study. Primary astrocyte cultures were prepared from the cortex of 6-day-old Sprague-Dawley rat pups [30]. The purity of primary cultured astrocytes was assessed using an astrocyte-specific marker, glial fibrillary acidic protein (GFAP), showing over 95\% GFAP-positive astrocytes. Cells were plated onto 12-well culture plates and made quiescent at confluence by incubation in serum-free DMEM/F-12 for $24 \mathrm{~h}$, and then incubated with $\mathrm{BK}$ at $37^{\circ} \mathrm{C}$ for the indicated time intervals. When the inhibitors were used, cells were pretreated with the inhibitor for $1 \mathrm{~h}$ before exposure to $\mathrm{BK}$.

\section{Animal model and experimental procedures}

All animals were treated in accordance with Chang Gung University guidelines, and the animal protocols were approved by Chang Gung University's Administrative Panel on Laboratory Animal Care. Male Sprague-Dawley rats (250-300 g) were anesthetized with Pentothal $(30 \mathrm{mg} / \mathrm{kg}, i . p$.$) and placed in a stereo-$ tactic frame. A 30 -gauge needle attached to a $1.0-\mathrm{ml}$ Hamilton microsyringe was inserted into the cortex via a polyethylene tube $(4.0 \mathrm{~mm}$ lateral to the midline, $2.0 \mathrm{~mm}$ anterior to the coronal suture of the bregma, $2.5 \mathrm{~mm}$ below the surface of the skull, and then withdrawn $0.5 \mathrm{~mm})$, and $30 \mu \mathrm{l}$ of $\mathrm{BK}(1 \mu \mathrm{M})$ was injected over 1 minute using a microsyringe pump. As a control experiment, $30 \mu \mathrm{l}$ of sterile $0.1 \%$ BSA was infused in the same way. After infusion, the needle was slowly removed. The burr hole was sealed with bone wax and the incision was closed. Rectal temperature was controlled within the normal range $\left(37 \pm 5^{\circ} \mathrm{C}\right)$ during surgery with a homeothermic blanket. The animals were maintained at $25^{\circ} \mathrm{C}$ with ad libitum access to food and water. To evaluate the involvement of ROS in BK-induced MMP-9 expression, the rats were pretreated with a ROS scavenger NAC $(150 \mathrm{mg} / \mathrm{kg}$, i.v. $)$ for $1 \mathrm{~h}$ before the BK injection for $24 \mathrm{~h}$. To examine the MMP-9 expression and astrocytes' localization in brain cortex, immunofluorescence staining was performed on the first and second serial sections of the brain, which were deparaffinized, rehydrated, and washed with PBS. Non-specific binding was blocked by preincubation with $\mathrm{PBS}$ containing 5\% BSA for $1 \mathrm{~h}$ at room temperature. The sections were incubated with an anti-MMP-9 or anti-GFAP antibody for the positive localization and identification of astrocytes for overnight at $4^{\circ} \mathrm{C}$. The sections were washed and then incubated with a fluorescein isothiocyanate (FITC)-conjugated goat anti-mouse or anti-rabbit secondary antibody and observed by using a fluorescence microscope (ZEISS, Axiovert $200 \mathrm{M}), 400 \times$.

\section{MMP gelatin zymography}

Growth-arrested cells were incubated with BK for the indicated time intervals. Treatment of RBA-1 cells with pharmacological inhibitors or BK alone had no significant effect on cell viability determined by an XTT assay (data not shown). The cultured media were analyzed by gelatin zymography [19]. Gelatinolytic activity was manifested as horizontal white bands on a blue background. Because cleaved MMPs were not reliably detectable, only pro-form zymogens were quantified.

\section{Total RNA extraction and reverse transcription-PCR analysis}

Total RNA was extracted from RBA-1 cells [19]. The cDNA obtained from $0.5 \mu \mathrm{g}$ total RNA was used as a template for PCR amplification. Oligonucleotide primers were designed on the basis of Genbank entries for rat MMP-9, Nox1-4 [17] and $\beta$-actin. The following primers were used for amplification reaction: MMP-9, 5'-AGTT TGGTGTCGCGGAGCAC-3' (sense), 5'-TACATGAGC GCTTCCGGCAC-3' (antisense); Nox1, 5'-TACGAAGT GGCTGTACTGGTTG-3' (sense), 5'-CTCCCAAAGGA GGTTT TCTGTT-3' (antisense); Nox2, 5'-TCAAGTGT CCCCAGGTATCC-3' (sense), 5'-CT TCACTGGCTGT ACCAAAGG-3' (antisense); Nox3, 5'-AATCACAGAG TC T GCCTGGACT-3' (sense), 5'-ATCCAGACTTTCA TCCCAGTGT-3' (antisense); Nox4, 5'-GGAAGTCCAT TTGAGGAGTCAC-3' (sense), 5'-TGGATGTTCACAA AGTCAGGTC-3' (antisense); $\beta$-actin, 5'-GAACCCTAA GGCCAACCGTG-3' (sense), 5'-TGGCATAGAGGTCT TTACGG-3' (antisense).

The amplification was performed in 30 cycles at $55^{\circ} \mathrm{C}$, $30 \mathrm{~s} ; 72^{\circ} \mathrm{C}, 1 \mathrm{~min} ; 94^{\circ} \mathrm{C}, 30 \mathrm{~s}$. PCR fragments were analyzed on $2 \%$ agarose in $1 \mathrm{X}$ TAE gel containing ethidium bromide and their sizes were compared to molecular weight markers. Amplification of $\beta$-actin, a relatively invariant internal reference RNA, was performed in parallel, and cDNA amounts were standardized to equivalent $\beta$-actin mRNA levels. These primer sets specifically recognize only the genes of interest as indicated by amplification of a single band of the expected size (754 bp 
for MMP-9, 337 bp for Nox1, 209 bp for Nox2, 214 bp for Nox3, 244 bp for Nox4, and 514 bp for $\beta$-actin).

\section{Preparation of cell extracts and Western blotting analysis} Growth-arrested cells were incubated with BK for the indicated time intervals. The cell lysates were collected and the protein concentration was determined by the $\mathrm{BCA}$ reagents according to the instructions of the manufacturer. Samples from these cell lysates $(30 \mu \mathrm{g}$ protein) were denatured and subjected to SDS-PAGE using a $10 \%(\mathrm{w} / \mathrm{v})$ running gel. The phosphorylation of $\mathrm{p} 47^{\text {phox }}$ or c-Jun was analyzed by Western blot [19]. The immunoreactive bands were detected by ECL reagents.

\section{Measurement of intracellular ROS generation}

The peroxide-sensitive fluorescent probe 2,7'-dichlorofluorescein diacetate (DCF-DA) was used to assess the generation of intracellular ROS [40] with minor modifications. RBA-1 cells on monolayers were incubated with $5 \mu \mathrm{M}$ DCF-DA in RPMI-1640 for $45 \mathrm{~min}$ at $37^{\circ} \mathrm{C}$. The supernatant was removed and replaced with fresh RPMI-1640 medium before exposure to BK (10 nM). Relative fluorescence intensity was recorded over time (3-120 min) by using a fluorescent plate reader (Thermo, Appliskan) at an excitation wavelength of $485 \mathrm{~nm}$ and emission was measured at a wavelength of $530 \mathrm{~nm}$, and fluorescent images were also obtained by using a fluorescence microscopy (ZEISS, Axiovert $200 \mathrm{M}$ ).

\section{Determination of NADPH oxidase activity by chemiluminescence assay}

The NADPH oxidase activity in intact cells was assayed by lucigenin chemiluminescence [41]. After incubation, the cells were gently scraped and centrifuged at $400 \times \mathrm{g}$ for $10 \mathrm{~min}$ at $4^{\circ} \mathrm{C}$. The cell pellet was resuspended in a known volume $(35 \mu \mathrm{l} /$ well $)$ of ice-cold RPMI 1640 medium, and the cell suspension was kept on ice. To a final $200 \mu \mathrm{l}$ of pre-warmed $\left(37^{\circ} \mathrm{C}\right)$ RPMI 1640 medium containing either NADPH $(1 \mu \mathrm{M})$ or lucigenin $(20 \mu \mathrm{M})$, $5 \mu \mathrm{l}$ of cell suspension $\left(2 \times 10^{4}\right.$ cells $)$ was added to initiate the reaction followed by immediate measurement of chemiluminescence using an Appliskan luminometer $\left(\right.$ Thermo $^{\circledR}$ ) in an out-of-coincidence mode. Appropriate blanks and controls were established, and chemiluminescence was recorded. Neither NADPH nor NADH enhanced the background chemiluminescence of lucigenin alone (30-40 counts/min). Chemiluminescence was continuously measured for $12 \mathrm{~min}$, and the activity of NADPH oxidase was expressed as counts per million cells.

\section{Transient transfection with siRNAs}

Transient transfection of small interfering RNA (siRNA) duplexes corresponding to rat PKC- $\alpha, \mathrm{p} 47^{\text {phox }}$,
Nox2, c-Fos, c-Jun, and scrambled siRNAs (100 nM) was performed using a Lipofetamine ${ }^{\mathrm{TM}}$ RNAiMAX reagent (Invitrogen) according to the manufacturer's instructions.

\section{Plasmid construction, transfection, and luciferase reporter gene assays}

The upstream region $(-1280$ to +19$)$ of the rat MMP-9 promoter was cloned to the pGL3-basic vector containing the luciferase reporter system [30]. Additionally, the introduction of a mismatched primer mutation into the AP-1 to generate pGL3-MMP-9 $\triangle \mathrm{AP}-1$ was performed, using the following (forward) primer: $\triangle \mathrm{AP}-1$ : 5'-GCAG GAGAGGAAGCTGAGTTGAAGACA-3'. All plasmids were prepared by using QIAGEN plasmid DNA preparation kits. These constructs were transfected into RBA-1 cells by using a Lipofectamine reagent according to the instructions of manufacture. The transfection efficiency ( $60 \%)$ was determined by transfection with enhanced GFP. After incubation with BK, cells were collected and disrupted by sonication in lysis buffer $(25 \mathrm{mM}$ Tris, $\mathrm{pH}$ 7.8, 2 mM EDTA, 1\% Triton X-100, and 10\% glycerol). After centrifugation, aliquots of the supernatants were tested for promoter activity using a luciferase assay system (Promega, Madison, WI). Firefly luciferase activities were standardized for $\beta$-galactosidase activity.

\section{Isolation of cell fractions}

Cells were harvested, sonicated for $5 \mathrm{~s}$ at output 1.5 with a sonicator (Misonix, Inc., Farmingdale, NY), and centrifuged at $8,000 \mathrm{rpm}$ for $15 \mathrm{~min}$ at $4^{\circ} \mathrm{C}$. The pellet was collected as the nuclear fraction. The supernatant was centrifuged at $14,000 \mathrm{rpm}$ for $60 \mathrm{~min}$ at $4^{\circ} \mathrm{C}$ to yield the pellet (membrane fraction) and the supernatant (cytosolic fraction).

\section{Measurement of intracellular $\mathrm{Ca}^{2+}$ level}

Intracellular $\mathrm{Ca}^{2+}$ signaling was measured in confluent monolayers with a calcium-sensitive dye Fura-2/AM as described by Grynkiewicz et al. [42]. Upon confluence, the cells were cultured in serum-free DMEM/F-12 for $24 \mathrm{~h}$ before measurements were made. The $\mathrm{Ca}^{2+}$ level was determined using Fura-2/AM as an indicator in a temperature-controlled holder of a Hitachi F-4500 spectrofluorometer (Tokyo, Japan), as previously described [19]. The autofluorescence of each monolayer was subtracted from the fluorescent data. The ratios $(R)$ of the fluorescence at the two wavelengths are computed and used to calculate changes in intracellular $\mathrm{Ca}^{2+}$ level.

\section{Immunofluorescence staining}

Growth-arrested cells were treated with $10 \mathrm{nM}$ BK for the indicated time intervals, washed twice with ice-cold PBS, fixed with $4 \%(\mathrm{w} / \mathrm{v})$ paraformaldehyde in PBS for 
$30 \mathrm{~min}$, and then permeabilized with $0.3 \%$ Triton X-100 in PBS for $15 \mathrm{~min}$. The staining was performed by incubating with $10 \%$ normal goat serum in PBS for $30 \mathrm{~min}$ followed by incubating with an anti-p $47^{\text {phox }}$ antibody (1:200 dilution) for $1 \mathrm{~h}$ in PBS with $1 \%$ BSA, washing thrice with PBS, incubating for $1 \mathrm{~h}$ with a FITCconjugated goat anti-rabbit antibody (1:200 dilution) in PBS with $1 \%$ BSA, washing thrice with PBS, and finally mounting with aqueous mounting medium. The images observed under a fluorescence microscope (ZEISS, Axiovert $200 \mathrm{M}$ ).

\section{Chromatin immunoprecipitation assay}

To detect the in vivo association of nuclear proteins with rat MMP-9 promoter, chromatin immunoprecipitation (ChIP) analysis was conducted as previously described [30]. Briefly, RBA-1 cells were cross-linked with $1 \%$ formaldehyde for $10 \mathrm{~min}$ at $37^{\circ} \mathrm{C}$ and washed thrice with ice-cold PBS containing $1 \mathrm{mM}$ phenylmethylsulfonyl fluoride (PMSF) and 1\% aprotinin. Soluble chromatin was prepared using a ChIP assay kit (Upstate) according to the manufacturer's recommendations and immunoprecipitated without (control) or with anti-c-Fos or antic-Jun antibody and normal goat immunoglobulin G (IgG). Following washes and elution, precipitates were heated overnight at $65^{\circ} \mathrm{C}$ to reverse cross-linking of DNA and protein. DNA fragments were purified by phenol-chloroform extraction and ethanol precipitation. The purified DNA was subjected to PCR amplification using the primers specific for the region $(-597$ to -318$)$ containing the distal AP-1 binding site $(-503$ to -497$)$ present in the MMP-9 promoter region, sense primer: 5'-AGAGCCTGCTCCCAGAGGGC-3'; antisense primer: 5'-GCCAAGTCAGGCAGGACCCC-3'. PCR fragments were analyzed on $2 \%$ agarose in $1 \mathrm{X}$ TAE gel containing ethidium bromide and the size (279 bp) was compared to a molecular weight marker.

\section{Cell migration assay}

RBA-1 cells were cultured to confluence in 6-well culture plates and starved with serum-free DMEM/F-12 medium for $24 \mathrm{~h}$. The monolayer cells were manually scratched with a pipette blue tip to create extended and definite scratches in the center of the dishes with a bright and clear field $(\sim 2 \mathrm{~mm})$. The detached cells were removed by washing the cells once with PBS. Serum-free DMEM/F-12 medium with or without BK $(10 \mathrm{nM})$ was added to each dish as indicated after pretreatment with the inhibitors for $1 \mathrm{~h}$, containing a DNA synthesis inhibitor hydroxyurea $(10 \mu \mathrm{M})$ during the period of experiment. Images of migratory cells from the scratched boundary were observed under a light microscope with a digital camera (Olympus, Japan). Numbers of migratory cells were counted from the resulting four phase images for each point and then averaged for each experimental condition. The data presented are summarized from three separate assays.

\section{Statistical analysis of data}

All the data were estimated using a GraphPad Prism Program (GraphPad, San Diego, CA). Data were expressed as the mean \pm SEM and analyzed by one-way analysis of variance followed with Tukey's posthoc test. $P<0.05$ was considered significant.

\section{Abbreviations \\ CNS: Central nervous system; BK: Bradykinin; MMP-9: Matrix metalloproteinase-9; RBA-1: Rat brain astrocytes; DMEM/F-12: Dulbecco's modified Eagle's medium/Ham's nutrient mixture F-12; FBS: Fetal bovine serum; ECL: Enhanced chemiluminescence; BCA: Bicinchoninic acid; PBS: Phosphate-buffered saline; GFAP: Glial fibrillary acid protein; GPCR: G protein-coupled receptor; NAC: N-acetyl cysteine; DPI: Diphenylene iodonium; TG: Thapsigargin; PKC-a: Protein kinase C-a; Nox2: NADPH oxidase 2; DCF-DA: 2',7'-dichlorodihydrofluorescin diacetate; ROS: Reactive oxygen species; siRNA: Small interfering RNA; TSIIA: Tanshinone IIA; RT-PCR: Reverse transcription-polymerase chain reaction; ChIP: Chromatin immunoprecipitation; AP-1: Activator protein 1.}

\section{Competing interests}

The authors declare that they have no competing interests.

\section{Authors' contributions}

$\mathrm{CCL}, \mathrm{RHS}, \mathrm{PLC}$, and SEC designed and performed experiments, acquisition and analysis of data, and drafted the manuscript. RHS and JCC helped to perform experiments and prepare the manuscript. HLH and CMY have conceived of the study, participated in its design and coordination, CMY has been involved in drafting the manuscript and revising it critically for important intellectual content and has given final approval of the version to be published. All authors read and approved the final version of manuscript.

\section{Acknowledgements}

This work was supported by the Ministry of Education, Taiwan; Grant number: EMRPD1B0311 and EMRPD1B0321; National Science Council, Taiwan; Grant number: NSC101-2321-B-182-013, NSC101-2320-B-182-039MY3, NSC99-2321-B182-003 and NSC98-2320-B-182-004-MY3; and NSC982320-B-255-001-MY3 and Chang Gung Medical Research Foundation, Grant number: CMRPG3B1091, CMRPG391033, CMRPD180373, and CMRPF1A0062.

\section{Author details}

'Department of Anesthetics, College of Medicine, Chang Gung University and Chang Gung Memorial Hospital at Linkuo, Kwei-San, Tao-Yuan, Taiwan. ${ }^{2}$ Department of Nursing, Division of Basic Medical Sciences, Chang Gung University of Science and Technology, Tao-Yuan, Taiwan. ${ }^{3}$ Department of Physiology and Pharmacology and Health Aging Research Center, College of Medicine, Chang Gung University, 259 Wen-Hwa 1st Road, Kwei-San, Tao-Yuan, Taiwan.

Received: 29 August 2012 Accepted: 14 November 2012 Published: 23 November 2012

\section{References}

1. Dollery CM, McEwan JR, Henney AM: Matrix metalloproteinases and cardiovascular disease. Circ Res 1995, 77:863-868.

2. Yong WW, Krekoski CA, Forsyth PA, Bell R, Edwards DR: Matrix metalloproteinases and diseases of the CNS. Trends Neurosci 1998, 21:75-80.

3. Yong W, Power C, Forsyth P, Edwards DR: Metalloproteinases in biology and pathology of the nervous system. Nat Rev Neurosci 2001, 2:502-511.

4. Gottschall PE, Yu X: Cytokines regulate gelatinase A, B (matrix metalloproteinase 2 and 9) activity in cultured rat astrocytes. J Neurochem 1995, 64:1513-1520. 
5. Lee WJ, Shin CY, Yoo BK, Ryu JR, Choi EY, Cheong JH, Ryu JH, Ko KH: Induction of matrix metalloproteinase-9 (MMP-9) in lipopolysaccharidestimulated primary astrocytes is mediated by extracellular signalregulated protein kinase 1/2 (Erk1/2). Glia 2003, 41:15-24.

6. Demchenko IT, Oury TD, Crapo JD, Piantadosi CA: Regulation of the brain's vascular responses to oxygen. Circ Res 2002, 91:1031-1037.

7. Halliwell B: Oxidative stress and neurodegeneration: where are we now? J Neurochem 2006, 97:1634-1658.

8. Chrissobolis S, Faraci FM: The role of oxidative stress and NADPH oxidase in cerebrovascular disease. Trends Mol Med 2008, 14:495-502.

9. Kamata $\mathrm{H}$, Hirata $\mathrm{H}$ : Redox regulation of cellular signalling. Cell Signal 1999, 11:1-14.

10. Chan PH: Reactive oxygen radicals in signaling and damage in the ischemic brain. J Cereb Blood Flow Metab 2001, 21:2-14.

11. Lewén $A$, Matz $P$, Chan PH: Free radical pathways in CNS injury. J Neurotrauma 2000, 17:871-890.

12. Qin L, Liu Y, Wang T, Wei SJ, Block ML, Wilson B, Liu B, Hong JS: NADPH oxidase mediates lipopolysaccharide-induced neurotoxicity and proinflammatory gene expression in activated microglia. $J \mathrm{Biol}$ Chem 2004, 279:1415-1421.

13. Chiang WC, Chien CT, Lin WW, Lin SL, Chen YM, Lai CF, Wu KD, Chao J, Tsai $\mathrm{TJ}$ : Early activation of bradykinin $\mathrm{B} 2$ receptor aggravates reactive oxygen species generation and renal damage in ischemia/reperfusion injury. Free Radic Biol Med 2006, 41:1304-1314.

14. Kamiya $T$, Katayama $Y$, Kashiwagi $F$, Terashi A: The role of bradykinin in mediating ischemic brain edema in rats. Stroke 1993, 24:571-575.

15. Chen CC, Chang J, Chen WC: Role of protein kinase $C$ subtypes $a$ and $\delta$ in the regulation of bradykinin-stimulated phosphoinositide breakdown in astrocytes. Mol Pharmacol 1995, 48:39-47.

16. Hsieh HL, Wang HH, Wu CY, Yang CM: Reactive Oxygen SpeciesDependent c-Fos/Activator Protein 1 Induction Upregulates Heme Oxygenase-1 Expression by Bradykinin in Brain Astrocytes. Antioxid Redox Signal 2010, 13:1829-1844.

17. Sato H, Seiki M: Regulatory mechanism of $92 \mathrm{kDa}$ type IV collagenase gene expression which is associated with invasiveness of tumor cells. Oncogene 1993, 8:395-405.

18. Zhu YM, Bradbury DA, Pang L, Knox AJ: Transcriptional regulation of interleukin (IL)-8 by bradykinin in human airway smooth muscle cells involves prostanoid-dependent activation of AP-1 and nuclear factor (NF)-IL-6 and prostanoid-independent activation of NF-kB. J Biol Chem 2003, 278:29366-29375.

19. Hsieh $\mathrm{HL}$, Yen $\mathrm{MH}$, Jou MJ, Yang CM: Intracellular signalings underlying bradykinin-induced matrix metalloproteinase- 9 expression in rat brain astrocyte-1. Cell Signal 2004, 16:1163-1176.

20. Hsieh HL, Wang HH, Wu WB, Chu PJ, Yang CM: Transforming growth factor- $\beta 1$ induces matrix metalloproteinase- 9 and cell migration in astrocytes: roles of ROS-dependent ERK- and JNK-NF-KB pathways. J Neuroinflammation 2010, 7:88

21. Wang $\mathrm{HH}$, Hsieh $\mathrm{HL}$, Yang $\mathrm{CM}$ : Calmodulin kinase II-dependent transactivation of PDGF receptors mediates astrocytic MMP-9 expression and cell motility induced by lipoteichoic acid. J Neuroinflammation 2010, 7:84.

22. Wang $\mathrm{HH}_{1}$, Hsieh $\mathrm{HL}$, Wu CY, Sun CC, Yang CM: Oxidized low-density lipoprotein induces matrix metalloproteinase-9 expression via a p42/p44 and JNK-dependent AP-1 pathway in brain astrocytes. Glia 2009, 57:24-38.

23. Nelson KK, Melendez JA: Mitochondrial redox control of matrix metalloproteinases. Free Radic Biol Med 2004, 37:768-784.

24. Infanger DW, Sharma RV, Davisson RL: NADPH oxidases of the brain: distribution, regulation, and function. Antioxid Redox Signal 2006 8:1583-1596.

25. Bedard K, Krause KH: The NOX family of ROS-generating NADPH oxidases: physiology and pathophysiology. Physiol Rev 2007, 87:245-313.

26. Wu CY, Hsieh HL, Sun CC, Yang CM: IL-1 $\beta$ induces MMP-9 expression via a $\mathrm{Ca}^{2+}$-dependent CaMKII/JNK/C-JUN cascade in rat brain astrocytes. Glia 2009, 57:1775-1789.

27. Lin CW, Shen SC, Chien CC, Yang LY, Shia LT, Chen YC: 12-Otetradecanoylphorbol-13-acetate-induced invasion/migration of glioblastoma cells through activating PKCa/ERK/NF-kB-dependent MMP-9 expression. J Cell Physiol 2010, 225:472-481.
28. Chatterjee N, Zou C, Osterman JC, Gupta NK: Cloning and characterization of the promoter region of a gene encoding a 67-kDa glycoprotein. J Biol Chem 1997, 272:12692-12698.

29. Rosenberg GA: Matrix metalloproteinases in neuroinflammation. Glia 2002, 39:279-291.

30. Hsieh HL, Wu CY, Yang CM: Bradykinin induces matrix metalloproteinase9 expression and cell migration through a PKC- $\delta$-dependent ERK/Elk-1 pathway in astrocytes. Glia 2008, 56:619-632.

31. Floyd RA: Neuroinflammatory processes are important in neurodegenerative diseases: an hypothesis to explain the increased formation of reactive oxygen and nitrogen species as major factors involved in neurodegenerative disease development. Free Radic Biol Med 1999, 26:1346-1355.

32. Lauffenburger DA, Horwitz AF: Cell migration: A physically integrated molecular process. Cell 1996, 84:359-369.

33. Abramov AY, Jacobson J, Wientjes F, Hothersall J, Canevari L, Duchen MRL: Expression and modulation of an NADPH oxidase in mammalian astrocytes. J Neurosci 2005, 25:9176-9184.

34. Kim SY, Lee JG, Cho WS, Cho KH, Sakong J, Kim JR, Chin BR, Baek SH: Role of NADPH oxidase-2 in lipopolysaccharide-induced matrix metalloproteinase expression and cell migration. Immunol Cell Biol 2010, 88:197-204

35. Fontayne A, Dang PM, Gougerot-Pocidalo MA, El-Benna J: Phosphorylation of $\mathrm{p} 47^{\text {phox }}$ sites by PKC $a, \beta I l, \delta$, and $\zeta$ : effect on binding to $p 22^{\text {phox }}$ and on NADPH oxidase activation. Biochemistry 2002, 41:7743-7750.

36. Sen CK, Packer L: Antioxidant and redox regulation of gene transcription. FASEB J 1996, 10:709-720.

37. Byun HJ, Hong IK, Kim E, Jin YJ, Jeoung DI, Hahn JH, Kim YM, Park SH, Lee $\mathrm{H}$ : A splice variant of CD99 increases motility and MMP-9 expression of human breast cancer cells through the AKT-, ERK-, and JNK-dependent AP-1 activation signaling pathways. J Biol Chem 2006, 281:34833-34847.

38. Noda M, Sasaki K, Ifuku M, Wada K: Multifunctional effects of bradykinin on glial cells in relation to potential anti-inflammatory effects. Neurochem Int 2007, 51:185-191.

39. Wu WS: The signaling mechanism of ROS in tumor progression. Cancer Metastasis Rev 2006, 25:695-705.

40. LeBel CP, Ischiropoulos H, Bondy SC: Evaluation of the probe 2'7'dichlorofluorescein as an indicator of reactive oxygen species formation and oxidative stress. Chem Res Toxicol 1992, 5:227-231.

41. Reinehr R, Görg B, Becker S, Qvartskhava N, Bidmon HJ, Selbach O, Haas HL, Schliess F, Häussinger D: Hypoosmotic swelling and ammonia increase oxidative stress by NADPH oxidase in cultured astrocytes and vital brain slices. Glia 2007, 55:758-771.

42. Grynkiewicz G, Poenie M, Tsien RY: A new generation of $\mathrm{Ca}^{2+}$ indicators with greatly improved fluorescence properties. J Biol Chem 1985, 260:3440-3450.

doi:10.1186/1478-811X-10-35

Cite this article as: Lin et al:: NADPH oxidase 2-derived reactive oxygen species signal contributes to bradykinin-induced matrix metalloproteinase- 9 expression and cell migration in brain astrocytes. Cell Communication and Signaling 2012 10:35.

\section{Submit your next manuscript to BioMed Central and take full advantage of:}

- Convenient online submission

- Thorough peer review

- No space constraints or color figure charges

- Immediate publication on acceptance

- Inclusion in PubMed, CAS, Scopus and Google Scholar

- Research which is freely available for redistribution 